\title{
Capital da dor: um monumento construído a partir dos escombros de todas as maravilhas dos années folles por Paul Éluard
}

Karine dos Santos Souza ${ }^{\mathrm{i}}$

\begin{abstract}
RESUMO
O presente artigo tem como principal objetivo trazer à tona a discussão da obra de Paul Éluard, poeta francês do século XX engajado politicamente e pouco traduzido para o português brasileiro. A obra aqui analisada é a antologia Capitale de la douleur, as discussões se embasam tanto na fortuna crítica produzida na França acerca da obra do poeta, quanto em teóricos relevantes para a crítica de poesia atual. A proposta de análise de dois poemas específicos da obra é apresentada na parte final do artigo.
\end{abstract}

Palavras-chave: Poesia; Surrealismo; Éluard; Capitale de la douleur.

\begin{abstract}
The present article aims to bring up the discussion of Paul Éluard's work, a French poet of the twentieth century who was politically engaged and poorly translated into Brazilian Portuguese. The work analyzed in this paperwork is the anthology Capital of pain, the discussions are based both on the critical fortune produced in France about the poet's work and on relevant theorists for the current poetry critique. The proposal of analysis of two specific poems is presented in the last part of the article.
\end{abstract}

Keywords: Poetry; Surrealism; Éluard; Capital of pain.

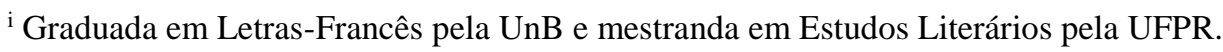

E-mail: souzakarine65@gmail.com 
O período dos anos vinte, também conhecido como "Les années folles", foi um momento de efervescência artística sem precedentes na história da cultura ocidental. Ainda que a contribuição artística para fazer deste período o que ele foi tenha vindo de todas as partes do mundo, foram, sobretudo, a França e os Estados Unidos que encabeçaram os movimentos da época. Como consequência, Henry Miller teria identificado onde estaria localizado o "umbigo do mundo" para os artistas naquele momento, esse lugar era Paris.

O credo progressista da época continuava abrindo espaço para um individualismo extravagante do qual André Gide e Marcel Proust deixaram indícios em seus romances. Tristan Tzara lança o manifesto do movimento dadaísta, e, logo em seguida, o surrealismo se agiganta através das artes visuais com Dalí, Max Ernst, Man Ray e Joan Miró, por exemplo; no cinema, as contribuições vêm através de Buñuel e Cocteau; na poesia serão os nomes de André Breton, Louis Aragon, Robert Desnos e Paul Éluard que irão se eternizar. Todos esses tendo vivido ou passado por Paris em algum momento de suas vidas.

Éluard nasceu no que hoje é conhecido como o subúrbio parisiense e passou a maior parte de sua vida nos arredores da capital, na região da "Île-de-France". Durante "Les années folles", Éluard vivia sua juventude em Paris e boa parte dos nomes citados acima passaram também por sua vida. O poeta teve uma vivência constituída por grandes intercâmbios culturais e intelectuais, sua poesia não seria diferente.

É nesse tempo e lugar que surge "Capitale de la douleur", poemas inéditos e não-inéditos são agrupados numa determinada ordem e seriam lançados inicialmente sob o título de "L'art d'être malheureux". No presente trabalho objetivamos tratar desta obra que foi, até o presente momento, tão pouco discutida no Brasil. Para tanto, levaremos em consideração trabalhos produzidos a respeito da antologia por pesquisadores especializados na obra do autor, sobretudo o estudo "Paul Éluard. Le Coeur absolu. Étude de Capitale de la douleur (1926)" de Corinne Bayle (2013) publicado pela Editora da Universidade de Rouen et du Havre (PURH), ao qual daremos um espaço privilegiado devido ao seu caráter abrangente e à sua análise convergente com trabalhos importantes para os estudos da poesia moderna, como os de Michel Murat e Laurent Jenny. Faremos breves pontuações distribuídas ao longo do texto de contextualizações biográficas, bem como trataremos de algo dos contextos 
histórico e artístico sob os quais a obra foi amalgamada. Tudo isso com o intuito de subsidiar as análises acerca da poética de Éluard e de localizar melhor o leitor em torno da obra. A isso, seguirá uma análise de dois poemas da coletânea. À conclusão, caberá uma breve recapitulação do trabalho.

\section{REDESCOBRINDO ÉLUARD}

Em 2013, Corinne Bayle publica um estudo sobre "Capitale de la douleur" reclamando o reconhecimento e um debruçar-se mais atento sobre a poesia de Éluard pela crítica universitária francesa; ainda que, assinala a autora, exista um interesse em ascensão no início do século XXI pelo surrealismo, movimento ao qual Éluard esteve vinculado. Se Éluard foi, de certa forma, ignorado pela crítica por mais de 30 anos em sua própria nação - mãe da língua francesa, e, consequentemente, a maior interessada no estudo da poesia produzida nesta língua - não é de se espantar que o poeta tenha recebido ainda menos atenção do outro lado do Atlântico. No Brasil, Éluard ficou conhecido como o poeta que ficara amigo de Manuel Bandeira durante a estadia de ambos no sanatório de Clavadel, em 1923. Graças ao poema "Liberdade", traduzido para o português por Bandeira em parceria com Drummond, Éluard fica conhecido aqui como o poeta da resistência.

As traduções de sua obra para o português brasileiro são parcas, logo, muito pouco há de fortuna crítica sobre sua obra no nosso país. A obra "Capitale de la douleur" é uma prova disso. Publicada em 8 setembro 1926 pela Nouvelle Revue Française (NRF), quando Éluard possui apenas 30 anos, a coletânea de poemas obtém um reconhecimento imediato pela crítica francesa. A partir desse momento, Éluard passa a ser considerado um grande poeta da então "nova geração", ao lado de outros grandes nomes da época como Valéry e Aragon.

Admirador de Apollinaire, assim como alguns outros colegas surrealistas, Éluard chegará a conhecer aquele que inaugurava o uso dos caligramas em língua francesa, apesar da morte precoce de Apollinaire em 1918. Quando Éluard começa a publicar seus primeiros poemas por conta própria, Apollinaire já havia lançado muitas de suas obras mais importantes, povoadas por uma preocupação com a criação de uma nova linguagem para a poesia francesa. No entanto, a produção poética de Éluard não parece 
receber uma influência tão forte daquele que por pouco não seria seu contemporâneo, como parece ter sido influenciado por uma tradição de poesia francesa menos avantgardiste. Segundo Bayle (2013), Éluard foi fortemente marcado pela leitura de Rimbaud, Baudelaire e Lautréamont. Ainda segundo a autora, a forte influência da poesia de Rimbaud poderia ser notada desde a escolha do poeta pelo uso de um pseudônimo: o primeiro nome dele é, na verdade, Eugène; ele escolhe usar seu terceiro nome - Paul - e substituir seu patronímico Grindel por Éluard, que era o sobrenome de sua avó materna. Desta forma, ele separava a sua identidade daquela do "eu" poético. Eugène Grindel na vida privada e Paul Éluard - o poeta, reenviando o público leitor à declaração rimbaudiana “Je est un autre" (BAYLE, 2013) [“Eu é um outro”].

Inserido nesse contexto profícuo da poesia francesa, esbarrando em grandes nomes da literatura à direita e à esquerda com outros colossos da pintura, da colagem e das artes plásticas num geral, por que foi que Éluard acabou recebendo um reconhecimento menor do que o que lhe era devido? Bayle (2013) afirma que por muito tempo Éluard ocupou o espaço do "lugar comum", enquanto poeta ele esteve "condenado" ao que muitos consideravam como um "sentimentalismo exacerbado" na poesia. Embora o poeta tenha buscado distanciar sua vida privada de sua carreira, talvez sua obra tenha sido percebida de tal maneira justamente porque sua vida privada fora, inevitavelmente, de interesse público (devido à notoriedade daqueles diretamente envolvidos: Gala, Max Ernst, Dalí). Ou talvez sejam a algumas características muito próprias de sua poesia, tais como a retomada do lirismo amoroso (FRÉMOND, 2008) e uma busca pela simplicidade, muitas vezes relacionada a uma produção "naïf" (SCHILLER, 1796 apud BAYLE 2013) que se devam essas considerações. É importante apontar que, ainda que essas sejam características da poética de Éluard, elas não são as únicas e que nem uma, nem a outra, são necessariamente características negativas em se tratando de poesia. Em seu estudo, a pesquisadora Corinne Bayle busca libertar Éluard dessa imagem do "lugar comum", tão perniciosa para um artista, através de uma análise detalhada e abrangente da obra "Capitale de la douleur" a qual ela descreverá na introdução de seu livro da seguinte forma:

[...] É na perspectiva de uma obra construída com plena consciência de todos os procedimentos complexos da métrica, do jogo de formas e imagens, com uma língua falsamente límpida, se inserindo em uma tradição para melhor lhe 
desfazer as armadilhas e libertar-se dela. (BAYLE, 2013, n.p. Tradução nossa)

Os complexos procedimentos métricos aos quais Bayle se refere não aparecem em "Capitale de la douleur" somente através dos poemas de versos alexandrinos (dodecassílabos), como em "L'égalité des sexes" ou através dos decassílabos e octossílabos, como em outros poemas presentes em "Nouveaux poèmes". Estes são poemas fiéis a uma tradição que Éluard nunca negou completamente e que, embora presentes na obra, seriam os poemas onde tais procedimentos são mais facilmente detectáveis. Por outro lado, estão igualmente presentes na obra poemas em versos livres e os procedimentos citados aparecem neles através de, por exemplo, aliterações e assonâncias.

As imagens, entendidas como procedimentos estéticos da poesia, também permeiam inteiramente "Capitale de la douleur". A obra apresenta poemas dedicados a Picasso e a Max Ernst, ambos artistas plásticos e amigos de Éluard. A proximidade do poeta com a linguagem visual, evidenciada não somente por um possível diletantismo, mas, precisamente por essa relação dialógica com artistas visuais, lhe permitia brincar com formas geométricas e imagens, transpassando-as para a linguagem poética. Não é sem motivos que a edição de 2008, publicada pela Folio, de "Capitale de la douleur" possui como capa a obra "Jeune fille devant un miroir", de Picasso. A edição é acrescida de uma análise de Alain Jaubert, que põe em evidência signos recorrentes tanto na obra poética quanto no quadro, que são notadamente: o espelho, a musa, formas circulares e corpos desarticulados. E o que seria melhor para justificar tais afirmações do que os próprios poemas? O diálogo entre as obras está evidentemente presente em poemas como "Le miroir d'un moment" (p. 128) e "La courbe de tes yeux..." (p. 134), falaremos do primeiro em detalhes mais à frente.

Quanto à influência de Max Ernst, vale dizer que a primeira edição independente de "Répétitions" é enriquecida por colagens feitas por ele e escolhidas por Éluard durante a estadia do casal Éluard em Colônia (Alemanha). Ernst e sua esposa moravam ali antes da mudança do mesmo para Paris, onde passará a dividir a mesma casa que Éluard e Gala. Ernst e Gala se envolverão amorosamente mais tarde.

Outra congruência de pensamento de Éluard, relatada por estudiosos de sua biografia, é a que o autor estabeleceu com Paulhan - escritor e futuro editor da 
Gallimard. Com Paulhan, Éluard terá longas discussões formais a respeito de provérbios, assunto que interessava muito aos dois, levando-os mesmo a lançar uma revista chamada "Proverbe", na qual publicarão juntos. Esse trabalho, feito em torno da pesquisa de provérbios em língua francesa, terá influência na composição de poemas presentes em "Capitale de la douleur" (BAYLE, 2013). Podemos observar na obra a presença de alguns versos que se assemelham muito a aforismos e que possuem, possivelmente, sua origem no trabalho feito durante a revista "Proverbe", como, por exemplo, em "Ce n'est pas la nuit que te manque, mais sa puissance" (p. 122).

\section{ÉLUARD, CRIADOR DE UMA POESIA ÉTICA E ESTÉTICA}

É importante salientar que Éluard teve a sua existência emaranhada aos acontecimentos históricos que deixariam marcas indeléveis em toda a humanidade. Aos 20 anos, ele foi um jovem que começava a publicar seus poemas em revistas no mês de abril e, um pouco mais tarde, no mesmo ano, estava se apresentando para servir seu país durante a Primeira Guerra Mundial. O poeta esteve no fronte trabalhando como enfermeiro durante dois anos de sua juventude. Aqueles de sua geração que, como ele, não morreram durante os sangrentos combates de 1914 ainda tiveram que testemunhar os horrores da Segunda Guerra, período no qual ele fez parte da resistência à ocupação alemã na França.

É com a publicação de "Poèmes pour la paix" - reunião de onze poemas sob título emblemático que sai para o público quase concomitantemente com o fim da guerra - que Éluard entra de forma definitiva no mundo da literatura francesa. Sua ideia de então era multiplicar esses onze poemas fazendo "nascer" de cada um deles outros dez. As reflexões e o trabalho feitos com a língua nesse projeto que nutrirão suas próximas obras (BAYLE, 2013), dentre elas o “Répétitions”, que ele publicará em 1922. Tendo isso em vista, é impossível que o caráter ético de sua poesia e a sua conduta engajada passem despercebidos em qualquer análise feita de seu trabalho.

No que tange ao universo artístico desse período tão violento que engendrará uma verdadeira crise de valores nas sociedades afetadas de modo mais imediato pela guerra, a resposta é instantânea: o movimento surrealista emerge como sequela criativa, como uma espécie de saída de emergência única para as dificuldades encontradas pelos 
intelectuais na tentativa de digerir o absurdo da guerra. A priori funcionando como um imã poderoso para todos os que buscavam novas possibilidades de criação na época, o movimento acaba se tornando sectarista; todos os que discordam em algum ponto da doutrina pregada por Breton acabam rompendo com ele e, consequentemente, sendo expulsos do grupo surrealista.

Mesmo participando das reuniões e partilhando o desejo de uma busca pela liberdade da expressão artística ao lado de seus contemporâneos, a poética de Éluard preservará "uma resposta através do lirismo de uma poesia superada, conservando uma forma de classicismo em seus versos" (BAYLE, 2013). Éluard se colocaria, neste contexto, em um entre-lugar: não totalmente vanguardista quanto seu antecessor direto, Apollinaire, tampouco totalmente adepto à doutrina da escrita automática defendida pelos surrealistas.

Ele não é o único poeta de sua geração que mantém algo da tradição dos alexandrinos em sua poesia, Aragon e Valéry estavam ainda mais ligados à tradição do que ele próprio. A característica diferencial de Éluard é que ele abrirá espaço em seus poemas para que conversem os versos livres e o clamor por uma nova linguagem poética, com a admiração e o orgulho de uma tradição que sempre fará parte dos pilares da construção de uma "nova possibilidade de linguagem" para a poesia.

Ademais, a geração dos surrealistas foi herdeira de uma crise anterior à crise moral causada pela guerra, o "Crise de vers" de Mallarmé aparece como uma outra cisão - esta, dentro do universo da poesia - da qual esses poetas, mais uma vez, não poderiam escapar incólumes. No entanto, para Éluard não parecia imperativo abandonar completamente os versos tradicionais trovadorescos ou a herança baudelairiana, por exemplo. Até mesmo porque o verso livre, longe de ser um mero desmonte irrefletido do verso clássico, assinala uma segmentação específica do discurso. E, ainda que não responda a uma organização interna tão rígida quanto à do alexandrino clássico, essa segmentação figura como uma das marcas essenciais da construção do poema, bem como as instituídas pelo ritmo (MURAT 2008 apud BAYLE 2013). Logo, o que podemos observar em Éluard é uma opção consciente pelo uso das antigas formas de maneira deformada, retorcida, transformada. Ele bebia um pouco de fontes clássicas, bem como das vanguardistas, para criar o seu estilo poético singular. 
Acerca desse estilo poético próprio, deve-se observar tanto o caráter retórico de seus poemas, quanto a relação entre forma e conteúdo (ou fond $x$ forme). Em um colóquio compartilhado através da revista Fabula, sob o título «Du livre ouvert au livre fermé: Éluard à rebours », o pesquisar Jean-François Puff (2013), ao analisar a figura da possessão amorosa nos poemas que têm Gala como musa, argumenta:

Le paradoxe de cette possession est que le poète en a une entière conscience ; il est lucide, il « distingue » bien ceci de cela, comme il est dit dans « Ne plus partager», par exemple «le vertige de la liberté »; au cœur de la folie d'amour il ne perd pas «cette clarté d'homme / qui est la (s)ienne » (89); il n'empêche que la passion douloureuse détermine le caractère difficile de cette poésie : comme il est dit dans «L'habitude» (58), au vent qui «se déforme » il faut «un habit sur mesure, / Démesuré »; le démesuré, le déformé, prennent volontiers dans le recueil la forme d'une fragmentation qui défait la continuité, et partant, l'intelligibilité du discours. ${ }^{1}$ (n.p.)

O pesquisador se refere a dois poemas de "Capitale de la douleur", o primeiro é "Ne plus partager", dedicado à Gala e inaugural da seção "Nouveaux poèmes"; o segundo é "L'habitude", localizado na seção "Mourir de ne pas mourir". As seções citadas estão separadas, no livro, por "Les petits justes", dos quais Puff falará em seguida:

C'est notable dans Répétitions, et ses poèmes faits de «copeaux » (dans «L'impatient» ou « À la minute» par exemple). Cette destruction de la parole « de commun échange entre nous » (cf. la préface de Les Animaux et leurs hommes) - on se rappelle que « les muets sont des menteurs » - est à référer directement à la figure de Gala, comme il est explicitement dit dans le poème VIII des « Petits justes » :

«Elle a toujours marché sous les arches des nuits

Et partout où elle a passé

Elle a laissé

L'empreinte des choses brisées. $»^{2}$ (Idem, n.p.)

Ou seja, para o pesquisador a forma fragmentada da coletânea apresenta uma intenção poética marcada: posto que a palavra deixa de funcionar como um instrumento eficaz de permuta entre interlocutores, o discurso, como consequência, fragmenta-se. A estrutura do poema se deforma para poder se conformar a ininteligibilidade do discurso, um discurso que é fruto não só da violência de uma paixão que não pode se realizar como o desejado pelo eu-lírico, mas também fruto de uma produção que se dá em um momento histórico em que a comunicação entre os homens se faz através da guerra; o discurso de um tempo no qual a própria moral humana se deforma e a realidade 
imediata deixa de corresponder à realidade construída socialmente por uma cultura ocidental pautada pela conduta da civilidade.

Puff (2013) defende Éluard como um poeta “do agir”, afirmando que em certos aspectos sua obra apresenta uma característica "de unidade", com uma perceptível continuidade nos planos formais, retóricos e temáticos. Sua análise nesse colóquio se concentra principalmente em duas obras do poeta, sendo uma delas "Capitale de la douleur". Puff traça paralelos entre biografia e os temas dos poemas de Éluard, sem, no entanto, oferecer análises simplistas ou desprovidas de uma reflexão acerca da linguagem poética.

\section{SITIANDO CAPITALE DE LA DOULEUR}

O título da obra é, por si só, um monumento. Mas antes de nomear assim o agrupamento de 113 poemas, Éluard havia encontrado uma outra fórmula. O que hoje podemos chamar, em português, de "Capital da dor", inicialmente se chamaria " $L$ 'art d'être malheureux", numa tradução livre "A arte de ser infeliz". Esse título, que acabou sendo dispensado, faz referência a um dos primeiros poemas da obra, intitulado, por sua vez, "L'invention". A antologia - cujos poemas que lhe dão forma, em sua maioria, não eram inéditos - teve sua primeira edição publicada em 1926.

A obra é dividida em quatro seções, são elas: "Répétitions", "Mourir de ne pas mourir", "Les petits justes" e "Nouveaux poèmes". Das quatro, todas possuem em sua composição poemas que já haviam sido publicados pelo poeta em outras circunstâncias, sendo que "Répétitions" e "Mourir de ne pas mourir" foram publicados como coletâneas independentes precedentemente, a primeira no ano de 1922 e a segunda em 1924. Falaremos em detalhes sobre cada uma dessas seções em seguida.

"Répétitions", seção inaugural da antologia, é composta por 35 poemas de formas variadas. A maioria dos poemas estão em versos heterométricos e centralizados na página, salvo por quatro exceções: o poema "Nul" (p. 18) e seu homônimo "Nul" (p. 24) têm forma prosaica; já o poema "L’invention" (p. 10) e "Ruban" (p. 36) possuem, ambos, formas híbridas: estão parcialmente versificados e parcialmente em prosa. A seção se introduz através do poema "Max Ernst". 
A segunda seção tem seu nome emprestado de um verso de Santa Tereza D'Avila "Que muero porque no muero", vertido para o francês por Éluard como "Mourir de ne pas mourir". Temos a impressão de que ao verter o verso para o francês, Éluard deixa um verso com forma interjetiva (em espanhol) para trazer um verso enunciativo (em francês), evocando muito mais uma reflexão a respeito do "não morrer" do que um lamento propriamente dito, facilmente identificável no verso originário da cantiga popular espanhola. A seção é subdividida em outros 22 poemas, desta vez com maiores variações entre verso e prosa. $\mathrm{O}$ primeiro poema dessa seção é dedicado à Breton, amigo do poeta e responsável pela escrita do manifesto surrealista ao qual Éluard foi filiado. Outros artistas surrealistas e/ou artistas que serviram de inspiração para estes primeiros são evocados nessa segunda parte, como, por exemplo, Giorgio de Chirico e Raymond Roussel.

"Les petits justes" é como é nomeada a terceira parte do livro, composta por 11 poemas de uma única estrofe cada, variando entre dísticos e sextetos. Os poemas recebem títulos em números romanos, indo de um a onze. A última seção, "Nouveaux poèmes", apesar do nome, não é composta somente por poemas inéditos, tendo em si alguns poemas já publicados anteriormente em revistas e catálogos de exposições. O número total de poemas que compõem essa última seção é de 45 , ela se inicia com um poema dedicado à Gala, intitulado "Ne plus partager". Nessa parte podemos encontrar alguns versos alexandrinos e todos os poemas estão alinhados à esquerda na página.

Dados biográficos indicam que antes de escrever essa seção Éluard deixa a França por alguns meses, fazendo viagens pelo mundo com o intuito de se afastar do casal Gala-Ernst. Ao que parece, fora Gala quem o convenceu a voltar alguns meses depois. Os poemas dessa seção também se dividem entre versificados e poemas em prosa, estando a segunda forma mais presente em "Nouveaux poèmes" do que em todas as seções precedentes do livro.

Segundo o que relata o próprio poeta, os poemas presentes nessa obra foram produzidos entre os anos de 1914 e 1926. Alguns estudiosos da obra do autor indicam que os poemas em prosa aumentam em número de produção de 1922 a 1926, informação que nos faz imaginar que talvez a organização da antologia tenha algo de cronológico, posto que na seção "Nouveaux poèmes" é onde se concentra o maior número de poemas em prosa. No entanto, segundo Bayle (2013), os 113 poemas que 
compõem a obra em sua completude não poderiam ser lidos nem como uma narrativa do percurso íntimo de encantos e desencantos amorosos do autor, nem, tampouco, como seu percurso de evolução estética na escrita (partindo do período das influências do movimento dada ao período de filiação ao surrealismo); pois, para a autora, a organização da obra não é tão cronológica quanto assemelha ser. Ainda segundo Bayle, a última seção conta com cinco textos escritos em 1921, ou seja, escritos em um momento anterior à produção de alguns poemas que figuram na primeira seção.

É também nessa última seção que se encontram os poemas que desejamos analisar: "Le miroir d'un moment" e "Ta chevelure d'oranges...”. Começaremos, então, pelo que aparece primeiro no livro:

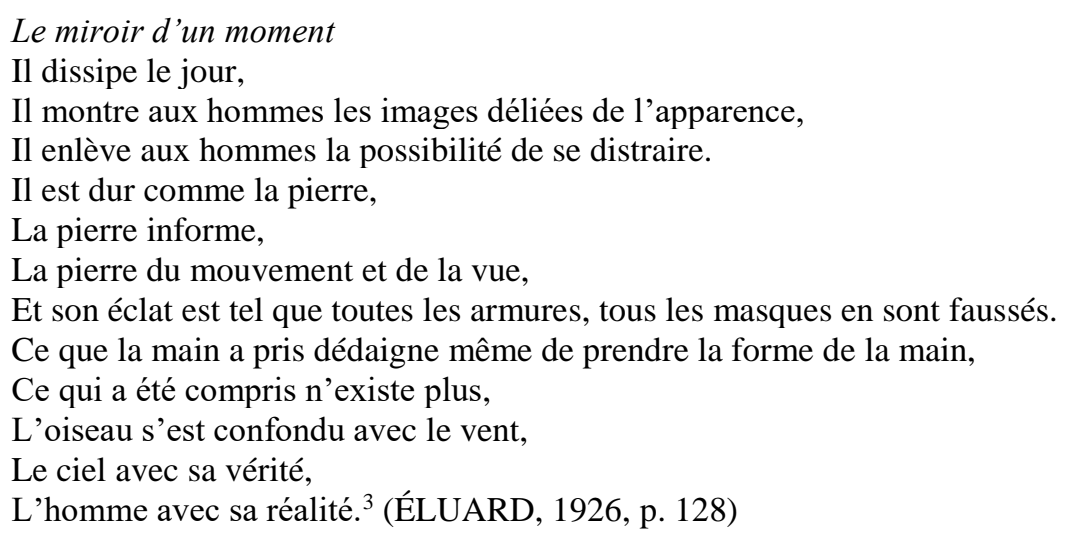

O poema aparece assim na obra: segmentado em 12 versos heterométricos, sem um padrão de rimas, agrupados em uma única estrofe. Passemos a uma observação semântica do poema. Do primeiro ao quarto versos o sujeito é o mesmo: "il”, o pronome "ele" em português, uma referência ao "espelho" do título. Cada um desses versos busca descrever um aspecto do objeto: "ele dissipa o dia", "ele mostra aos homens as imagens delineadas da aparência", "ele subtrai aos homens a possiblidade de se distrair" e "ele é duro como a pedra,"; os outros três versos que seguirão parecem ser uma continuação deste último, acrescentando características ao sintagma "a pedra": "a pedra informe,/ a pedra do movimento e da vista,/ e sua resplandescência é tal que todas as armaduras, todas as máscaras se falseiam a partir dela”. Em seguida, o próximo verso se inicia com o pronome "ce", que poderia ser traduzido para o português como "aquilo"; o novo sujeito dos próximos versos: “Aquilo que a mão pegou desdenha até mesmo de tomar a forma da mão," e "Aquilo que foi compreendido não existe mais,". Esses dois versos 
parecem buscar descrever o reflexo visto no espelho dos primeiros versos. Já os versos seguintes se apresentam como um desdobramento do último: "O pássaro se confundiu com o vento,", "O céu com a sua verdade," e "O homem com a sua realidade.", aqui temos uma memória das coisas antes delas começarem a confundirem-se, antes de coisas que pareciam ter um significado muito bem estabelecido começarem a tornar-se mais fluídas e a falsearem-se mutuamente.

Como argumentamos mais acima, o emaranhamento de forma e conteúdo pode ser compreendido como uma estratégia estética da poesia de Éluard. Logo, partindo de uma compreensão semântica do poema e preconizando que ela pudesse influenciar assim a estrutura dele, podemos imaginar que esse poema se divide em três estrofes. Não havendo marcas tipográficas para nos indicar a separação dessas estrofes, elas seriam indicadas por unidades de sentido. Cada uma das três estrofes possui uma unidade de sentido da qual os versos giram em torno, notadamente: o espelho, o reflexo e a memória anterior ao reflexo.

O poema que sucede ao "Le miroir d'un moment" não possui título e é constituído, por sua vez, por três tercetos, observemos:

Ta chevelure d'oranges dans le vide du monde Dans le vide des vitres lourdes de silence

Et d'ombre où mes mains nues cherchent tous tes reflets.

La forme de ton coeur est chimérique

Et ton amour ressemble à mon désir perdu

O soupirs d'ambre, rêves, regards.

Mais tu n'as pas toujours été avec moi. Ma mémoire

Est encore obscurcie de t'avoir vu venir

Et partir. Le temps se sert de mots comme l'amour. ${ }^{4}$ (ÉLUARD, 1926, p. 129)

Neste poema, os versos variam entre dodecassílabos, hendecassílabos, eneassílabos e versos de quatorze sílabas. Na primeira estrofe, uma imagem: os cabelos da musa ou a ideia dos cabelos de vívida cor da musa, cujos reflexos as mãos do eulírico buscam desarmadas, em um pesado vazio de silêncio e sombra. Essa sombra parece nos reenviar ao primeiro verso do poema da página anterior "Il dissipe le jour,". O objeto do qual giramos em torno ainda é o mesmo: o espelho. No verso seguinte: "A forma do teu coração é quimérica", o adjetivo usado poderia ser interpretado tanto por sua acepção metafórica, um coração que possui uma forma que é fruto da imaginação 
do eu-lírico; quanto por sua acepção literal que reenvia à figura mitológica da Quimera - um monstro de aspecto híbrido, com um corpo de leão, uma cabeça de cabra saindo das costas e um rabo de serpente. A interpretação simbólica desta figura indica uma relação complexa do inconsciente, que através de criações imaginárias busca representar desejos insatisfeitos, fontes de frustrações (CHEVALIER e GHEERBRANT, 1969). Os versos seguintes denunciam: "E teu amor se assemelha ao meu desejo perdido. / Ô suspiros de âmbar, sonhos, olhares.”. Essa estrofe parece conversar com aquela hipotética segunda estrofe do poema anterior: "la pierre informe" / "la forme de ton coeur est chimérique", "ô soupirs d'ambre, (...) regards" / "la pierre du mouvement et de la vue". Na derradeira estrofe, são os verbos vir e partir que se destacam, dando a ideia de movimento, de tempo e de memória. A memória obscurecida na qual confundem-se: "l'oiseau avec le vent, / le ciel avec sa vérité, / l'homme avec sa réalité".

$\mathrm{Na}$ edição por nós utilizada da obra, os dois poemas estão em páginas que se opõem, podendo ser observados concomitantemente com o livro aberto. A hipótese que levantamos com essa análise é a de que se trate de um mesmo poema, disposto na antologia de modo que uma parte possa estar em frente à outra, como uma figura disposta frente a um espelho, confundindo-se mutuamente a imagem e o reflexo da imagem.

Retornamos à argumentação de Bayle (2013), que parece corroborar com a nossa análise através de um diálogo com Laurent Jenny (1990) em sua obra "La Parole singulière":

\begin{abstract}
Ainsi, l'hétérométrie frappante dans Capitale de la douleur fait varier les vitesses du poème et instaure un effet particulier de suspens, d'attente, d'interrogation, prolongé par le blanc, relayé par l'alternance des poèmes en vers et en prose, des poèmes en vers libres et en vers mesurés. Le sens est différé, la parole se déploie selon un rythme qui tient autant au silence qu'au dit : selon Laurent Jenny, «chaque vers se veut une "unité de pensée" qui, au coup par coup, se mesure à l'espace de son déploiement typographique, ainsi qu'en témoigne l'élasticité de la ligne ». [...] L'aspect pictural de ce vers polymorphe, qui fabrique un poème différent pour l'œil, [...] le poème posé sur la page mettant en scène la peinture, ou faisant lui-même tableau; à cela s'ajoute la dimension onirique du poème en prose, frappante chez les précurseurs du XIX siècle. $^{5}$ (BAYLE, 2013, n.p)
\end{abstract}

Tanto a ideia do poema fazendo-se quadro, quanto o conceito de uma palavra que se desdobra segundo um ritmo que tem a ver tanto com o silêncio quanto com o 
dito, nos foram caros para a elaboração desta análise. Sem dúvidas os espaços em branco têm um papel fundamental na construção imagética desse poema, bem como o ritmo é fundamental em sua segunda parte, marcada por assonâncias. Não restam dúvidas de que a teoria de Laurent Jenny corrobora a compreensão e interpretação que apresentamos como possível da obra de Éluard, fornecendo não só uma nova perspectiva acerca do verso livre, mas, na verdade, um olhar apurado para texto lírico de forma mais abrangente.

\section{CONSIDERAÇÕES FINAIS}

Esperamos, com este trabalho, ter fornecido suficientes informações acerca da obra "Capitale de la douleur" e dos contextos sociais e culturais em que viveu e produziu Paul Éluard, a fim, não só de viabilizar as análises propostas na parte final do trabalho, como também de despertar, no leitor brasileiro, um interesse pela obra.

O único trabalho tradutório da obra de Paul Éluard para o português de que temos conhecimento é a coletânea "Poemas", de José Paulo Paes (1988), publicada pela editora Guanabara e já esgotada. Um trabalho de crítica a essas traduções também já foi realizado através da dissertação “José Paulo Paes tradutor de Paul Éluard” (2009), mas muito pouco movimento em torno da obra de Éluard foi percebido, o que é considerado por nós como uma grande perda para o público brasileiro.

Como buscamos demonstrar neste trabalho, a obra "Capitale de la douleur" é resultante de um verdadeiro trabalho poético e acaba por fundar seus próprios modelos, merecendo, desta forma, um olhar mais atento e um respeito a sua integridade enquanto conjunto de poemas pensados através das relações estabelecidas no interior da própria obra. Ansiamos por novos trabalhos feitos acerca dessa obra e esperamos ter contribuído para as discussões não somente no âmbito da obra de Éluard no Brasil, mas globalmente no da poesia.

\section{Referências}

BAYLE, Corinne. PAUL ÉLUARD. LE COEUR ABSOLU - Étude de Capitale de la douleur. Collection: Chefs-d'œuvre de la littérature française. Éditeur: Presses 
universitaires de Rouen et du Havre (2013) Disponível em:

https://books.openedition.org/purh/5587 18/06/2019. Acesso em 26 de junho de 2019.

CHAREST, Nelson. Michel Murat, Le Vers libre. Paris, Honoré Champion, coll. « Littérature de notre siècle », 2008, p. 325.

CHEVALIER, Jean et GHEERBRANT, Alain. Dictionnaire des symboles,

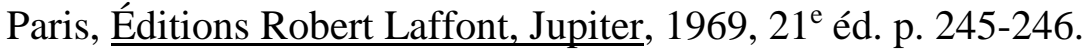

DOS SANTOS, Giovana Bleyer Ferreira. “José Paulo Paes tradutor de Paul Éluard”, dissertação de mestrado em Letras - UnB, 2009.

ÉLUARD, Paul. Capitale de la douleur. éd. Folio Plus Classique, Gallimard. Paris, 1926.

FRÉMOND, Émilie. «Le texte en perspective » em Capitale de la douleur. Gallimard, 2008, p. 167.

FONTVIEILLE-CORDANI, Agnès « Des lieux communs dans Capitale de la douleur », Fabula / Les colloques, Eluard, Capitale de la douleur, URL : http://www.fabula.org/colloques/document2239.php página consultada em 25 jun. 2019.

JAUBERT, Alain. « Lecture d'image » em Capitale de la douleur. Gallimard, 2008, p. 145 .

JENNY, Laurent. La Parole singulière, Paris, Belin, « L'extrême contemporain », 1990, p. 117.

MURAT, Michel. Le vers libre. Paris, Champion, 2008 («Littérature de notre siècle»).

PAES, José Paulo. Poemas ed. Guanabara, 1988.

PUFF, Jean-François, « Du livre ouvert au livre fermé : Éluard à rebours », Fabula / Les colloques, Eluard, Capitale de la douleur, URL :

http://www.fabula.org/colloques/document2244.php, página consultada em 24 jun 2019.

SCHILLER, Friedrich. De la poésie nä̈ve et sentimentale, Sylvain Fort (trad.), Paris, L'Arche, 2002. 


\begin{abstract}
${ }^{1}$ Tradução livre: O paradoxo dessa possessão é que o poeta tem inteira consciência dela; ele é lúcido, ele "distingue" bem isso daquilo, como é dito em "Ne plus partager", por exemplo, "a vertigem da liberdade"; no auge da loucura amorosa ele não perde "essa clareza de homem / que é a sua"; o que não impede que a paixão dolorosa determine o caráter difícil dessa poesia: como é dito em "L'habitude", no vento que "se deforma" é preciso "vestes sob medida / desmedidas (no sentido de imoderado); o desmedido, o deformado, tomam na coletânea uma forma de fragmentação que desfaz a continuidade, e consequentemente, a inteligibilidade do discurso.

2 Tradução livre: É notável em "Répétitions" e seus poemas feitos de aparas (em "L'impatient" ou "à la minute", por exemplo). Essa destruição da palavra "de intercâmbio comum entre nós" (cf. o prefácio de "Les animaux et leurs hommes") - nos lembramos que "os mudos são mentirosos" - se refere diretamente a figura de Gala, como é dito explicitamente no poema VIII dos "Petits justes":
\end{abstract}

"Ela sempre andou sob os arcos das noites

E em toda parte por onde ela passou

Ela deixou

O rastro das coisas despedaçadas."

3 Tradução livre*: O espelho de um momento

Ele dissipa o dia,

Ele mostra aos homens as imagens desvinculadas da aparência,

Ele subtrai dos homens a possibilidade de se distrair.

Ele é duro como a pedra,

A pedra disforme,

A pedra do movimento e da visão,

E sua luminosidade é tal que todas as armaduras, todas as máscaras, falseiam-se.

Aquilo que a mão pegou desdenha até mesmo de tomar a forma da mão,

O que foi compreendido não existe mais,

O pássaro confundiu-se com o vento,

O céu com sua verdade,

O homem com sua realidade.

* Lembramos que aqui não fizemos o trabalho de uma tradução preocupada com a conservação da métrica do poema, bem como não nos atentamos aos padrões rítmicos no momento da tradução. Não é a nossa intenção, neste artigo, propor uma tradução cuidadosa dos poemas. Isso exigiria um trabalho de outra natureza. Nos contentamos, aqui, com uma tradução quase literal, de modo que possamos proporcionar ao leitor do artigo uma compreensão global dos aspectos semânticos dos poemas citados durante a análise.

${ }^{4}$ Tua cabeleira de laranjas no vazio do mundo

No vazio dos vidros pesados de silêncio

E de sombra onde minhas mãos nuas buscam todos os teus reflexos.

A forma do teu coração é quimérica

E teu amor se assemelha ao meu desejo perdido

Ó suspiros de âmbar, sonhos, olhares.

Mas tu não esteves sempre comigo. Minha memória

Ainda está obscurecida de te ter visto vir 
E partir. O tempo se serve das palavras como o amor.

${ }^{5}$ Tradução livre: Assim, a heterometria marcante em "Capitale de la douleur" faz variar as velocidades do poema e instaura um efeito peculiar de suspense, de espera, de interrogação, prolongado pelo branco, transmitido pela alternância dos poemas em verso e em prosa, dos poemas em versos livres e em versos metrificados. O sentido é diferido, a palavra se desdobra segundo um ritmo que deve tanto ao silêncio quanto ao dito: segundo Laurent Jenny, "cada verso se quer uma "unidade de pensamento" que, aos poucos, se mede pelo espaço de seu desdobramento tipográfico, assim como testemunha a elasticidade da linha". (...) O aspecto pictural desse verso polimorfo que fabrica um poema diferente para o olho, (...) o poema colocado sobre a página põe em cena a pintura, ou compõe, ele mesmo, um quadro; a isto se adiciona a dimensão onírica do poema, marcante nos precursores do século XIX. 